\title{
Feline Interstitial Cystitis Enhances Mucosa-Dependent Contractile Responses to Serotonin
}

\author{
Youko Ikeda ${ }^{1,2}$, Amanda Wolf-Johnston ${ }^{1}$, James R. Roppolo ${ }^{2}$, Charles A. T. Buffington ${ }^{3}$, Lori Birder ${ }^{1,2}$ \\ ${ }^{1}$ Division of Renal-Electrolyte, Department of Medicine, School of Medicine, University of Pittsburgh, Pittsburgh, PA, USA \\ ${ }^{2}$ Department of Pharmacology and Chemical Biology, University of Pittsburgh, Pittsburgh, PA, USA \\ ${ }^{3}$ Department of Veterinary Clinical Sciences, The Ohio State University, Columbus, OH, USA
}

Purpose: To determine whether responses to serotonin are altered in bladder strips from cats diagnosed with a naturally occurring form of bladder pain syndrome/interstitial cystitis termed feline interstitial cystitis (FIC).

Methods: Full thickness bladder strips were isolated from aged matched healthy control cats and cats with clinically verified FIC. Bladder strips were mounted in an organ bath and connected to a tension transducer to record contractile activity. A serotonin dose response $(0.01-10 \mu \mathrm{M})$ was determined for each strip with the mucosa intact or denuded.

Results: Bladder strips from control and FIC cats contracted in response to serotonin in a dose-dependent manner. The normalized force of serotonin-evoked contractions was significantly greater in bladder strips from cats with FIC $(n=7)$ than from control cats $(n=4)$. Removal of the mucosa significantly decreased serotonin-mediated responses in both control and FIC bladder preparations. Furthermore, the contractions in response to serotonin were abolished by $1 \mu \mathrm{M}$ atropine in both control and FIC bladder strips.

Conclusions: The effect of serotonin on contractile force, but not sensitivity, was potentiated in bladder strips from cats with FIC, and was dependent upon the presence of the mucosa in control and FIC groups. As atropine inhibited these effects of serotonin, we hypothesize that, serotonin enhances acetylcholine release from the mucosa of FIC cat bladder strips, which could account for the increased force generated. In summary, FIC augments the responsiveness of bladder to serotonin, which may contribute to the symptoms associated with this chronic condition.

Keywords: Interstitial cystitis; Serotonin; Urothelium

- Grant support: This study was supported by NIH/NIDDK (R01 DK057284 and R01 DK115476 to L. Birder).

- Research Ethics: All animal experiments described received ethical approval by the University of Pittsburgh and Ohio State University's Institu-

tional Animal Care and Use Committee and were conducted in accordance with the NIH guide for the care and use of laboratory animals.

- Conflict of Interest: No potential conflict of interest relevant to this article was reported.

\section{- HIGHLIGHTS}

- Feline interstitial cystitis increases detrusor contractile response to serotonin.

- The enhanced serotonin response is dependent upon the presence of the mucosa.

- Serotonin mediated contractions involves activation of muscarinic receptor pathways.

Corresponding author: Youko Ikeda (iD https://orcid.org/0000-0001-9774-1523 Division of Renal-Electrolyte, Department of Medicine, School of Medicine, University of Pittsburgh, A1219 Scaife Hall, Pittsburgh, PA 15261, USA E-mail: yoi4@pitt.edu / Tel: +1-412-383-5939 / Fax: +1-412-648-7197 Submitted: December 8, 2018 / Accepted after revision: December 13, 2018
This is an Open Access article distributed under the terms of the Creative Commons Attribution Non-Commercial License (http://creativecommons.org/licenses/by-nc/4.0/) which permits unrestricted non-commercial use, distribution, and reproduction in any medium, provided the original work is properly cited. 


\section{INTRODUCTION}

Serotonin exerts complex effects on the lower urinary tract [1,2]. Serotonin binds to 5-hydroxtrytamine (5-HT) receptors, and a variety of 5-HT receptors have been demonstrated in the urinary bladder [3-6]. Serotonin has been implicated in centrally mediated control over urinary bladder function in cats, where serotonin-containing parasympathetic and sympathetic neurons from the lumbosacral cord and Onuf's nucleus innervate the lower urinary tract. In vivo cystometry studies in cats have indicated that within the spinal cord, $5-\mathrm{HT}_{2}$ receptors stimulate urethral sphincter activity, whereas inhibitory effects on the bladder are mediated $5-\mathrm{HT}_{1}$-receptors [1]. Serotonin also can affect bladder function peripherally, having been shown to induce or facilitate detrusor contractions in isolated bladders from various species including humans. The bladder mucosa also responds to serotonin [7] and could potentially modulate contractile function of the detrusor. However, the physiological significance of the peripheral 5-HT receptor activity in the urinary bladder has yet to be fully elucidated.

Expression of bladder 5-HT receptors has been shown to change in pathological conditions such as partial bladder outlet obstruction [8] or benign prostatic hyperplasia [9]. Furthermore, 5 -HT receptor expression also may be modulated by chronic stress. Lonne-Rahm et al. [10] reported an increase in epidermal fraction of 5- $\mathrm{HT}_{1 \mathrm{~A}}$ receptor and serotonin transporter protein immunoreactivity in the involved skin of patients with atopic dermatitis during chronic stress. An increase in mast cells in the involved skin also was observed, and these cells were often located close to the basement membrane. Interestingly, local increases in mast cell numbers has been suggested to be a common link among a variety of stress responsive inflammatory conditions, such atopic dermatitis, interstitial cystitis (IC) and irritable bowel syndrome, in which mast cells are activated without allergic degranulation [11], although the role of mast cells in nonulcerative (F)IC has yet to be resolved [12]. There also appears to be a correlation between increased 5-HT receptor expression and lower cortisol ratios [10], an indicator of chronic stress. Low cortisol concentrations also have been reported in both human [13] and cats [14] with (F)IC. Therefore, there is evidence that chronic inflammatory conditions such as (F)IC might impact serotonergic signaling.

Serotonin can directly induce detrusor smooth muscle contraction in cat bladders [15]. It has also been demonstrated to facilitate presynaptic acetylcholine $(\mathrm{ACh})$ release from cholin- ergic nerves [16] and potentially affect nonneuronal transmitter release [17] in bladders of other animal models. However, the effects of feline interstitial cystitis (FIC) on the physiological effects of serotonin have not been reported to our knowledge. The aim of this study was to determine if FIC induces alterations in bladder responses to serotonin.

\section{MATERIALS AND METHODS}

\section{Animals}

All cats with FIC were diagnosed at The Ohio State University (OSU) Veterinary Teaching Hospital and obtained as donations from clients using criteria previously described [18]. Control cats were obtained from commercial vendors and determined to be healthy and free of disease using to the same diagnostic criteria as those applied to cats with FIC. All subjects were housed in the OSU animal facility and acclimated for at least three months prior to transport to the University of Pittsburgh for use in experiments.

\section{Bladder Excision}

Urinary bladders were excised from deeply anesthetized ( $\alpha$-chloralose $60-70 \mathrm{mg} / \mathrm{kg} ; 98 \% \mathrm{O}_{2}: 2 \%$ isoflurane) cats as previously described $[19,20]$. Briefly, adequate anesthesia was determined by testing for absence of withdrawal reflex of the hind paw and absence of eye blink reflex to tactile stimulation of the medial canthus. After removal of the bladder, cats were euthanized via overdose of anesthetic.

\section{Tissue Contractility}

Strips approximately $5 \mathrm{~mm}$ in width were cut from the dome to the neck of bladders obtained from control and FIC cat bladders. Strips were mounted in an organ bath with the outlet (neck) end of the strips pinned to the fixed platform. The recording chamber was fabricated from thermally conductive, electrically insulating heat-conducting epoxy resin and the dome was attached to a tension transducer (WPI, Sarasota, FL, USA). Tissues were superfused with Tyrode’s solution with 95\% $\mathrm{O}_{2} / 5 \% \mathrm{CO}_{2}$ and allowed to equilibrate at for at least 30 minutes at $37^{\circ} \mathrm{C}$. Serotonin $(0.01-10 \mu \mathrm{M})$ was added to the perfusion bath and washed out for 15 to 30 minutes between each intervention with superfusion of Tyrode's solution. Tension data were recorded and analyzed in LabChart 5 (AD Instruments, Colorado Springs, CO, USA). 


\section{Solutions and Chemicals}

Tyrode's solution was composed of the following in $\mathrm{mM}: \mathrm{NaCl}$, 118; $\mathrm{NaHCO}_{3}, 25 ; \mathrm{KCl}, 4.7 ; \mathrm{MgCl}_{2} .6 \mathrm{H}_{2} \mathrm{O}, 1.2 ; \mathrm{CaCl}_{2}$, 1.8; glucose, 14 ; Na pyruvate, 5.0, gassed with $\mathrm{O}_{2} / \mathrm{CO}_{2}(95 \% / 5 \%) ; \mathrm{pH}$ 7.4. Serotonin and atropine were added to the Tyrode's solution as aliquots from $10 \mathrm{mM}$ stocks (distilled water) made fresh for each experiment. All chemicals were purchased from SigmaAldrich (St. Louis, MO, USA).

\section{Data and Statistical Analysis}

Data from tension recordings were expressed as mean \pm standard error and ' $n$ ' indicates the number of experiments. Dose-response plots were fitted to $\mathrm{T}=\left(\mathrm{T}_{\max } \times[\mathrm{A}]^{\mathrm{n}}\right) /\left(\mathrm{EC}_{50}{ }^{\mathrm{n}}+[\mathrm{A}]^{\mathrm{n}}\right)$, where $\mathrm{T}$ is the contraction magnitude, $\mathrm{T}_{\max }$ is the maximum tension at the highest agonist concentration, $[\mathrm{A}]$ is the agonist concentration, $\mathrm{n}$ is a constant, and $\mathrm{EC}_{50}$ is the agonist dose at $\mathrm{T}_{\max } / 2$. The dose-response curves were fitted using Kaleidagraph4.1 (Synergy Software, Reading, PA, USA). Wilcoxon ranked sum tests were performed to determine differences between FIC versus control preparations and mucosa intact versus denuded data sets. The null hypothesis was rejected at $\mathrm{P}<0.05$.

\section{RESULTS}

\section{Serotonin Induced Contractions Were Potentiated In Bladder Strips From Cats With FIC}

Both control and FIC cat bladder strips contracted in response to serotonin in a dose dependent manner $(0.01-10 \mu \mathrm{M})$ (Fig. 1A, B). Bladder strips from cats with FIC developed significantly greater amounts of force (normalized to cross-sectional area) than did strips from control cat bladders in response to serotonin (maximal force $\mathrm{T}_{\max }$ ) (Table 1). Dose response curves (Fig. 1A, B) from control and FIC strips revealed that although FIC bladder strips generated more force at higher concentrations, they had lower sensitivity to serotonin than control cat bladder strips, however, this value did not reach statistical significance (Table 1). Furthermore, serotonin-evoked contractions were inhibited by pretreating bladder strips from control cats with the

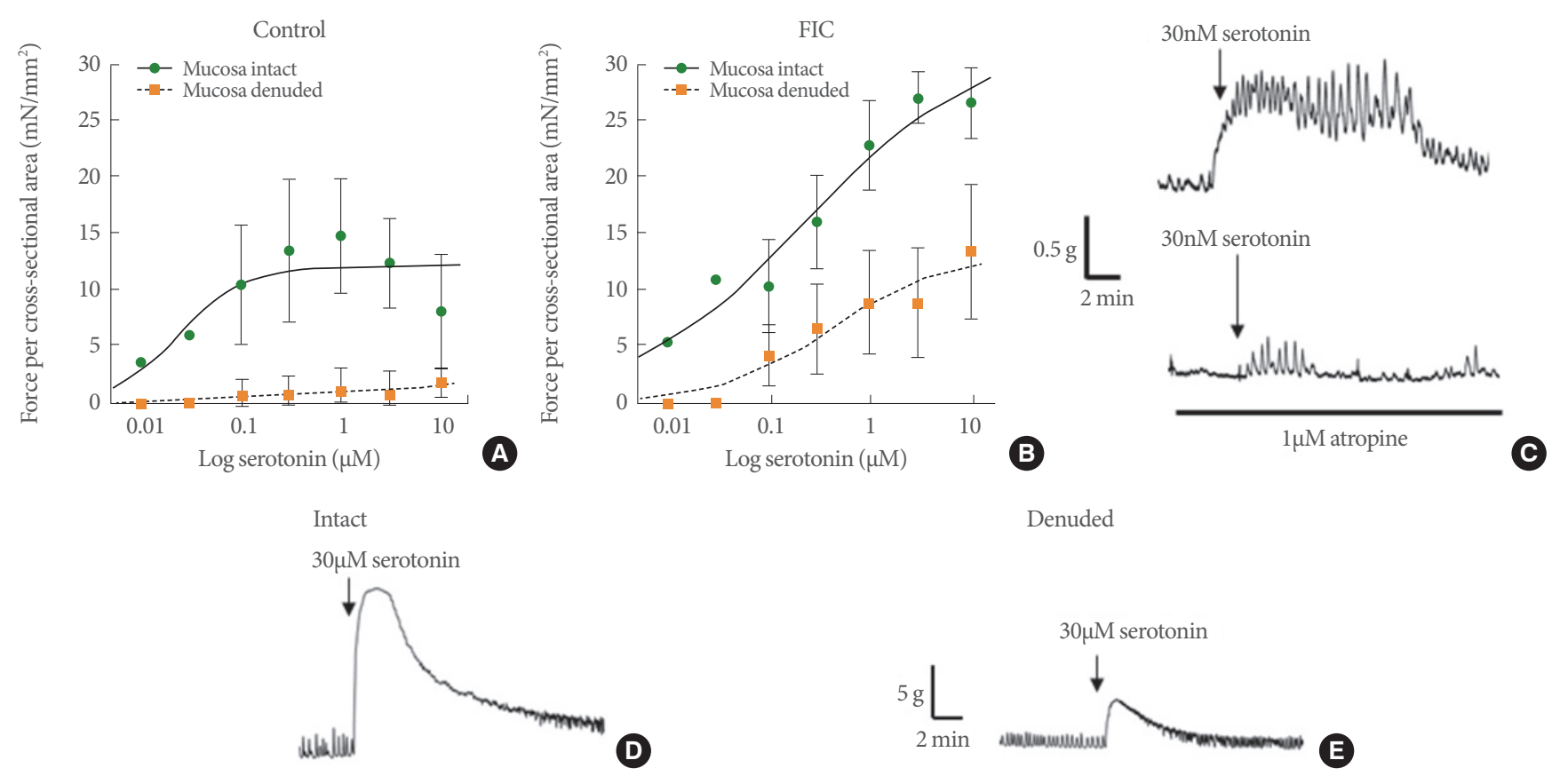

Fig. 1. Serotonin dose-response curves from mucosa intact and denuded control and feline interstitial cystitis (FIC) cat bladder strips. (A) Serotonin dose-response curve from control cat bladder strips with and without the mucosa. (B) Serotonin dose-response from FIC cat bladder strips with and without the mucosa. (C) Example tension traces from control cat bladder strip demonstrating contractile response to $30 \mathrm{nM}$ serotonin and its inhibition by pretreatment with $1 \mu \mathrm{M}$ atropine. (D) Example tension trace from a mucosa intact control cat bladder strip contracted with $30 \mu \mathrm{M}$ serotonin. (E) Representative response of contraction evoked by $30 \mu \mathrm{M}$ serotonin in a mucosa denuded control cat bladder strip. Comparable responses were obtained in mucosa intact and denuded FIC preparations (not shown). 
Table 1. Calculated values of serotonin dose-response of control and FIC bladder strips

\begin{tabular}{llccc}
\hline Treatment & Group & Sample $(\mathrm{n})$ & $\mathrm{T}_{\max }\left(\mathrm{mN} / \mathrm{mm}^{2}\right)$ & $\mathrm{EC}_{50}(\mu \mathrm{M})$ \\
\hline Intact & FIC & 6 & $27.2 \pm 2.5^{*}$ & $0.23 \pm 0.15$ \\
& Control & 4 & $12.9 \pm 4.0$ & $0.15 \pm 0.09$ \\
Denuded & FIC & 6 & $17.9 \pm 7.6^{*}$ & $1.5 \pm 1.0^{\dagger}$ \\
& Control & 3 & $2.5 \pm 1.3$ & $\mathrm{NA}^{\mathrm{a})}$ \\
\hline
\end{tabular}

Values are represented as mean \pm standard error.

FIC, feline interstitial cystitis; $\mathrm{T}_{\max }$, maximal force generated; $\mathrm{EC}_{50}$, effective concentration at half-maximal force; $\mathrm{mN}$, milli Newtons.

${ }^{*} \mathrm{P}<0.05$, FIC versus control. ${ }^{\dagger} \mathrm{P}=0.04$, intact versus denuded; Unpaired Wilcoxon ranked sums test. ${ }^{\text {a) }} \mathrm{EC}_{50}$ value could not be obtained because a contractile response could not be obtained in all strips.

muscarinic antagonist, $1 \mu \mathrm{M}$ atropine (Fig. 1C). The inhibitory effect of atropine was also observed in FIC bladder strips (not shown).

\section{Removal of the Mucosa Decreased Responsiveness to Serotonin}

Blunt dissection of the mucosa decreased the $T_{\max }$ value in response to serotonin (Fig. 1A, B, D, E) in both control and FIC strips (Table 1). This was accompanied by a significant decrease in potency (half-maximal effective concentration, $\mathrm{EC}_{50}$ ) in the FIC preparations. A dose response curve and $\mathrm{EC}_{50}$ value could not be obtained in control denuded bladder strips as a contractile response could not be obtained in all strips.

\section{DISCUSSION}

This study demonstrated an enhanced response of bladder strips from cats with FIC to serotonin, which was reduced in the absence of the mucosa. Serotonin-evoked contractions also were inhibited by the muscarinic antagonist, atropine suggesting that they were mediated by release of ACh. This is consistent with previously described effects of serotonin-induced contractions in bladder strips from guinea-pigs and human beings $[5,16]$.

Activation of peripheral 5-HT receptors has been shown to induce contractions of mucosa-denuded rat and guinea pig bladder strips in a dose-dependent manner [3,5]. These muscle strip studies suggested that 5-HT receptor activation could cause direct release of neurotransmitters from motor nerves. In contrast, our studies suggest that there is a significant contribution of the mucosa to the serotonin-mediated contraction, a finding that also has been observed in porcine bladder strips
[7]. Denuded FIC preparation demonstrated a dose dependent contractile response which was virtually absent in control bladder strips. This implies that serotonin induced contractions in normal cat bladders are mediated almost exclusively by structures in the mucosa and that in FIC preparations, the detrusor muscle or innervating efferent nerves have enhanced responses to serotonin. Results from this study showed serotonin $\mathrm{EC}_{50}$ value for control cat bladders was lower than FIC preparations, suggesting a higher sensitivity in normal cat mucosa. However, the difference between control and FIC $\mathrm{EC}_{50}$ values did not reach statistical significance due to the limited sample numbers available for the study.

There is a heterogeneous population of 5-HT receptors expressed throughout the bladder [5]. The function of 5-HT receptors in the urothelium/suburothelium of the cat bladder has not yet been fully characterized. However, if there is a stimulatory relationship of neuronal and potentially nonneuronal ACh release and 5-HT receptors, this could make the mucosa a major source of ACh release. Previous studies have demonstrated urothelial cells from FIC cats [19] and IC patients [21] more readily released adenosine triphosphate (ATP) in response to mechanical distention compared to controls. Urothelial ATP release could be further stimulated by activation of 1,4,5-triphosphate pathways, and this effect was more pronounced in FIC preparations [19]. Furthermore, mucosal muscarinic receptor activity is enhanced in bladder mucosa from cats with FIC [20], suggesting that these receptors may contribute to enhancement of urothelial ATP release. In contrast, there are reports that endogenous serotonin produced by the urothelium has an inhibitory effect on stretch-evoked urothelial ATP release $[17,22]$ in other species, suggesting that serotonin could dampen ATP mediated activation of suburothelial sensory nerves. Whether this mechanism is present in cat urothelial cells was not determined in this study.

Serotonin is believed to play a key role in sensory modulation of the urethra that can also affect bladder function. Serotonin containing paraneurons have been described in rodent and human urethral epithelium which make close contact with innervating sensory and cholinergic fibers [23,24]. Interurethral serotonin or urethral distension were shown to potentiate nociceptive responses [24] and bladder reflex contractions [23]. Changes in systemic serotonin levels could also influence urethral paraneurons to induce urinary frequency and/or enhance nociceptive responses. Therefore, additional investigation of urethral 5-HT signaling could yield important information on 


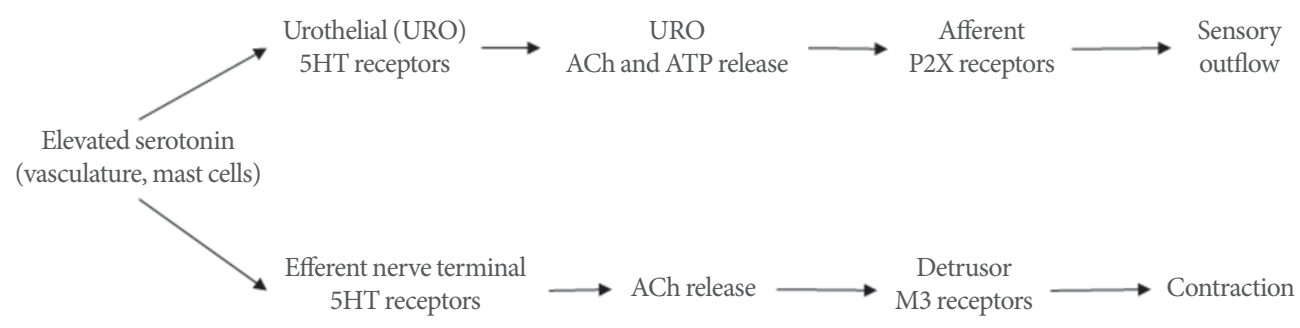

Fig. 2. Hypothetical sites and mechanism of action for serotonin in the cat urinary bladder wall. 5-HT, 5-hydroxtrytamine; Ach, acetylcholine; ATP, adenosine triphosphate.

the lower urinary tract pathophysiology of FIC.

The effects of serotonin in the central nervous system have also been investigated in relation to BPS/IC pathophysiology. The efficacy of duloxetine, a serotonin/norepinephrine reuptake inhibitor, treatment was examined in IC patients, based on its approved use for treatment of chronic pain conditions. However, the study did not demonstrate significant benefits to IC symptoms at the dose used $[25,26]$. In the context of the findings from this study, serotonin could potentially exacerbate detrusor contractile responses in FIC. As such, increasing endogenous serotonin concentrations may not be beneficial for alleviating bladder symptoms in IC.

Taken together these data suggest enhanced responsiveness of bladder strips from cats with FIC. Whereas the force developed in mucosa-intact strips from control cats seemed to plateau at approximately $0.1 \mu \mathrm{M}$ serotonin, the force developed in mucosa-intact strips from cats with FIC continued to rise beyond $10 \mu \mathrm{M}$, approximately a 100 -fold difference. Previous studies have demonstrated that serotonin can enhance neuronal ACh release as well as directly contract the bladder $[3,7,15,16]$. Although the cellular source of ACh released by serotonin was not elucidated in this study, it appears to be localized mainly to the mucosa. Furthermore, the urothelium is capable of synthesizing and releasing ACh in response to stretch $[27,28]$ and that FIC bladder strips have enhanced contractile responses to muscarinic agonists, where the mucosa was the main site of action [20]. Thus, it can be hypothesized that there may be higher concentrations of endogenous or circulating serotonin in FIC combined with increased sensitivity of the bladder. Serotonin may trigger the nonneuronal release of ACh activating urothelial muscarinic receptors to potentiate stretch-evoked ATP release $[29,30]$ and in turn activating innervating sensory nerves (Fig. 2). This dysregulated activation of bladder sensory nerves could account for bladder pain syndrome/IC (BPS/IC) symptoms such as discomfort or pain during filling. Further investi- gation of serotonergic signaling within the lower urinary tract will be important to determine the role in functional pain syndromes such as BPS/IC.

\section{AUTHOR CONTRIBUTION STATEMENT}

- Full access to all the data in the study and takes responsibility for the integrity of the data and the accuracy of the data analysis: $Y I, C A T B, L B$

- Study concept and design: $Y I, L B$

- Acquisition of data: $Y I$

- Analysis and interpretation of data: $Y I$

- Drafting of the manuscript: YI

- Critical revision of the manuscript for important intellectual content: YI, CATB, $L B$

- Statistical analysis: $Y I$

- Obtained funding: $L B$

- Administrative, technical, or material support: $A W, J R R$

- Study supervision: $L B$

\section{REFERENCES}

1. de Groat WC. Influence of central serotonergic mechanisms on lower urinary tract function. Urology 2002;59(5 Suppl 1):30-6.

2. Michel MC, Peters SL. Role of serotonin and noradrenaline in stress urinary incontinence. BJU Int 2004;94 Suppl 1:23-30.

3. Kim HJ, Lee G, Kim DH, Lee SJ, Yoon DK, Cho JH. Acute effects of serotonin on rat bladder contractility. Urol Int 2002;68:44-8.

4. Lychkova AE, Pavone LM. Role of serotonin receptors in regulation of contractile activity of urinary bladder in rabbits. Urology 2013;81:696.e13-8.

5. Yoshida A, S-Yamashita Y, Kaibara M, Taniyama K, Tanaka N. 5-Hydroxytryptamine receptors, especially the 5-HT4 receptor, in guinea pig urinary bladder. Jpn J Pharmacol 2002;89:349-55.

6. Michishita M, Yano K, Kasahara K, Tomita K, Matsuzaki O. In- 
creased expression of 5- $\mathrm{HT}(2 \mathrm{~A})$ and $5-\mathrm{HT}(2 \mathrm{~B})$ receptors in detrusor muscle after partial bladder outlet obstruction in rats. Biomed Res 2015;36:187-94.

7. Moro C, Edwards L, Chess-Williams R. 5-HT2A receptor enhancement of contractile activity of the porcine urothelium and lamina propria. Int J Urol 2016;23:946-51.

8. Khan MA, Dashwood MR, Thompson CS, Mumtaz FH, Morgan RJ, Mikhailidis DP. Time-dependent up-regulation of neuronal 5-hydroxytryptamine binding sites in the detrusor of a rabbit model of partial bladder outlet obstruction. World J Urol 1999;17:255-60.

9. Imamura T, Ishizuka O, Ogawa T, Minagawa T, Ishikawa M, Hiragata $\mathrm{S}$, et al. Expression of 5-hydroxytryptamine receptors in human urinary bladders with benign prostatic hyperplasia. Adv Ther 2015;32 Suppl 1:29-37.

10. Lonne-Rahm SB, Rickberg H, El-Nour H, Mårin P, Azmitia EC, Nordlind K. Neuroimmune mechanisms in patients with atopic dermatitis during chronic stress. J Eur Acad Dermatol Venereol 2008;22:11-8.

11. Theoharides TC, Cochrane DE. Critical role of mast cells in inflammatory diseases and the effect of acute stress. J Neuroimmunol 2004;146:1-12.

12. Erickson DR, Tomaszewski JE, Kunselman AR, Stetter CM, Peters $\mathrm{KM}$, Rovner ES, et al. Urine markers do not predict biopsy findings or presence of bladder ulcers in interstitial cystitis/painful bladder syndrome. J Urol 2008;179:1850-6.

13. Buffington CA. Comorbidity of interstitial cystitis with other unexplained clinical conditions. J Urol 2004;172(4 Pt 1):1242-8.

14. Westropp JL, Welk KA, Buffington CA. Small adrenal glands in cats with feline interstitial cystitis. J Urol 2003;170(6 Pt 1):2494-7.

15. Cohen ML, Drey K. Contractile responses in bladder body, bladder neck and prostate from rat, guinea pig and cat. J Pharmacol Exp Ther 1989;248:1063-8.

16. D’Agostino G, Condino AM, Gallinari P, Franceschetti GP, Tonini M. Characterization of prejunctional serotonin receptors modulating $[3 \mathrm{H}]$ acetylcholine release in the human detrusor. J Pharmacol Exp Ther 2006;316:129-35.

17. Matsumoto-Miyai K, Yamada E, Shinzawa E, Koyama Y, Shimada S, Yoshizumi M, et al. Serotonergic regulation of distention-induced ATP release from the urothelium. Am J Physiol Renal Physiol 2016;310:F646-55.

18. Buffington CA, Chew DJ, Kendall MS, Scrivani PV, Thompson SB, Blaisdell JL, et al. Clinical evaluation of cats with nonobstructive urinary tract diseases. J Am Vet Med Assoc 1997;210:46-50.

19. Birder LA, Barrick SR, Roppolo JR, Kanai AJ, de Groat WC, Kiss S, et al. Feline interstitial cystitis results in mechanical hypersensitivity and altered ATP release from bladder urothelium. Am J Physiol Renal Physiol 2003;285:F423-9.

20. Ikeda Y, Birder L, Buffington C, Roppolo J, Kanai A. Mucosal muscarinic receptors enhance bladder activity in cats with feline interstitial cystitis. J Urol 2009;181:1415-22.

21. Sun Y, Chai TC. Augmented extracellular ATP signaling in bladder urothelial cells from patients with interstitial cystitis. Am J Physiol Cell Physiol 2006;290:C27-34.

22. Mansfield KJ, Hughes JR. Effect of inflammatory mediators on ATP release of human urothelial RT4 cells. Biomed Res Int 2014; 2014:182862.

23. Coelho A, Oliveira R, Cavaleiro H, Cruz CD, Cruz F. Evidence for an urethro-vesical crosstalk mediated by serotonin. Neurourol Urodyn 2018;37:2389-97.

24. Kullmann FA, Chang HH, Gauthier C, McDonnell BM, Yeh JC, Clayton DR, et al. Serotonergic paraneurones in the female mouse urethral epithelium and their potential role in peripheral sensory information processing. Acta Physiol (Oxf) 2018 Feb;222(2). https:// doi.org/10.1111/apha.12919.

25. van Ophoven A, Hertle L. The dual serotonin and noradrenaline reuptake inhibitor duloxetine for the treatment of interstitial cystitis: results of an observational study. J Urol 2007;177:552-5.

26. Papandreou C, Skapinakis P, Giannakis D, Sofikitis N, Mavreas V. Antidepressant drugs for chronic urological pelvic pain: an evidencebased review. Adv Urol 2009;2009:797031.

27. Hanna-Mitchell AT, Beckel JM, Barbadora S, Kanai AJ, de Groat WC, Birder LA. Non-neuronal acetylcholine and urinary bladder urothelium. Life Sci 2007;80:2298-302.

28. Lips KS, Wunsch J, Zarghooni S, Bschleipfer T, Schukowski K, Weidner W, et al. Acetylcholine and molecular components of its synthesis and release machinery in the urothelium. Eur Urol 2007; 51:1042-53.

29. McLatchie LM, Young JS, Fry CH. Regulation of ACh release from guinea pig bladder urothelial cells: potential role in bladder filling sensations. Br J Pharmacol 2014;171:3394-403.

30. Young JS, Matharu R, Carew MA, Fry CH. Inhibition of stretchingevoked ATP release from bladder mucosa by anticholinergic agents. BJU Int 2012;110(8 Pt B):E397-401. 